\title{
Traditional uses, phytochemical study and morphological characterization of Pistacia lentiscus L. fruits from three areas of northern Algeria
}

\author{
Kaissa Boudieb1, Sabrina Ait Slimane- Ait Kaki', Hayet Amellal-Chibane1 \\ ${ }^{1}$ University M'Hamed Bougara of Boumerdes, 35000, Algeria, Faculty of Sciences, Laboratory of Soft Technology, \\ Valorization, Physico-chemistry of the Biological Materials and Biodiversity. \\ Corresponding Author: E-mail: k.boudieb@univ-boumerdes.dz \\ Original submitted in on $14^{\text {th }}$ January 2019. Published online at www.m.elewa.org/journals/ on $31^{\text {st }}$ March 2019 \\ https://dx.doi.org/10.4314/jab.v135i1.5
}

\begin{abstract}
Objectives: The present study aimed at the valorization of Pistacia lentiscus L. (lentisk, mastic tree), hence, an ethnobotanical investigation, phytochemical screening and morphological study of fruits from three areas of northern Algeria was carried out.

Methodology and Results: Ethnobotanical data were recorded from herbalists, pharmacists and people living in contact with medicinal plants in the three study areas (Boumerdes, Tizi-Ouzou and Bouira), using a questionnaire to collect as much information on traditional uses and virtues of lentisk. Screening was performed for various biochemical compounds. Biometric measurements and the weight of 1000 seeds from three locations were conducted and compared. According to the data collected, over $90 \%$ of the surveys in the three regions have knowledge of lentisk. The consensus value for a part of the plant (CPP) revealed that $P$. lentiscus fruit represented by the fixed oil is most used in the region of Bouira. However, leaves represent the highest use values in the other regions. A number of diseases treated with $P$. lentiscus have been identified. These are mainly respiratory and digestive disorders. Lentisk was also indicated for the treatment of circulatory disorders and skin allergies, with varying percentages depending on the region. Phytochemical screening of this plant showed that fruits from different areas were rich in anthocyanins, condensed tannins, Gallic tannins and flavonoids. While they were free of saponosides and alkaloids. A significant difference in the weight of the 1000 seeds and the average seed weight was obtained between the fruits of the three zones, which may be due to climatic factors.

Conclusions and application of findings: The results obtained constitute a valuable source of information, which should be the subject of additional pharmacological studies as antimicrobial, antinflamatory, hepatoprotective, and antiatherogenic activities, to validate their popular use and to isolate bioactive compounds that can also be used as ingredients of functional foods.
\end{abstract}

Keywords: Ethnobotany, Pistacia lentiscus L., phytochemical screening, Morphological study.

\section{INTRODUCTION}

Medicinal plants are already known as a natural source of a range of bioactive compounds. Therefore, the researchers today are emphasizing on evaluation and characterization of various plants and plant constituents against a number of diseases based on their traditional claims (Tiwari et al., 2011; Gupta et al., 2015). Algeria is characterized by a diverse climate and topography, 
which are favourable for the development of a flora rich in aromatic and medicinal plants (Azzi et al., 2012). Lentisk (Pistacia lentiscus L.), evergreen shrub of the family Anacardiaceae producing bright red globose berries. It develops in several Mediterranean regions (Dhifi et al., 2013) and is generally dispersed in Algeria all along the coast. The fruits, galls, resin and leaves of $P$. lentiscus have a long tradition in folk medicine dating back to the time of the ancients Greeks (Charef et al., 2008). The aerial part traditionally used in the treatment of arterial hypertension thanks to its diuretic properties. The leaves are provided with anti-inflammatory, antibacterial, antifungal, antipyretic, astringent, and hepatoprotective, expectorant and stimulant activities. They are also used in the treatment of eczema, oral infections,

\section{MATERIALS AND METHODS}

Description of the Study Area: Geographic coordinates, bioclimatic characteristics of the sites of diarrhoea, kidney stones, jaundice, headaches, asthma and respiratory problems. The essential oil of lentisk is known for its therapeutic virtues with regard to lymphatic and circulatory problems (Hafsé et al., 2015). Despite its wealth, there are few studies related to ethnobotanical research and phytochimecal composition of Pistacia lentiscus L. fruits published in the literature. In the present study, ethnobotanical survey is part of the objective of collecting all the information on the therapeutic and traditional applications of $P$. lentiscus in three towns of northern Algeria, (Boumerdes, Bouira and Tizi-Ouzou). This study was also to investigate the $P$. lentiscus berries growing in these areas for its phytochemical composition and morphological characterization.

Pistacia lentiscus L. samples and the study area are indicated in the Table 1 and Fig.1.

Table 1: Geographic coordinates and bioclimatic characteristics of the sites of Pistacia lentiscus L. samples

\begin{tabular}{lcccc}
\hline Stations & $\begin{array}{c}\text { Latitude } \\
(\mathbf{N})\end{array}$ & $\begin{array}{c}\text { Longitude } \\
(\mathrm{E})\end{array}$ & $\begin{array}{c}\text { Altitude } \\
(\mathbf{m})\end{array}$ & $\begin{array}{c}\text { Average temperature } \\
\left({ }^{\circ} \mathbf{C}\right)\end{array}$ \\
\hline Bouira (Tikejda) & $36^{\circ} 23$ & $03^{\circ} 53$ & 555 & 17.5 \\
Boumerdes (Dellys) & $36^{\circ} 55$ & $03^{\circ} 57$ & 08 & 18.3 \\
Tizi-Ouzou (Azazga) & $36^{\circ} 42$ & $04^{\circ} 03$ & 188 & 19.2 \\
\hline
\end{tabular}

(Data from the meteorological station at Dar El Beida)

Plant material: The mature fruits of Pistacia lentiscus L. (lentisk-mastic tree) (Fig. 2), were harvested in three localities in Northern Algeria (Table 1). Part of the plant material was dried at room temperature for two weeks, then were finely ground using a coffee grinder to allow a good extraction of biomolecules. The powders were stored in bottles protected from light until use. The other part was used to assess the morphological characteristics of the seeds of the three study areas. 


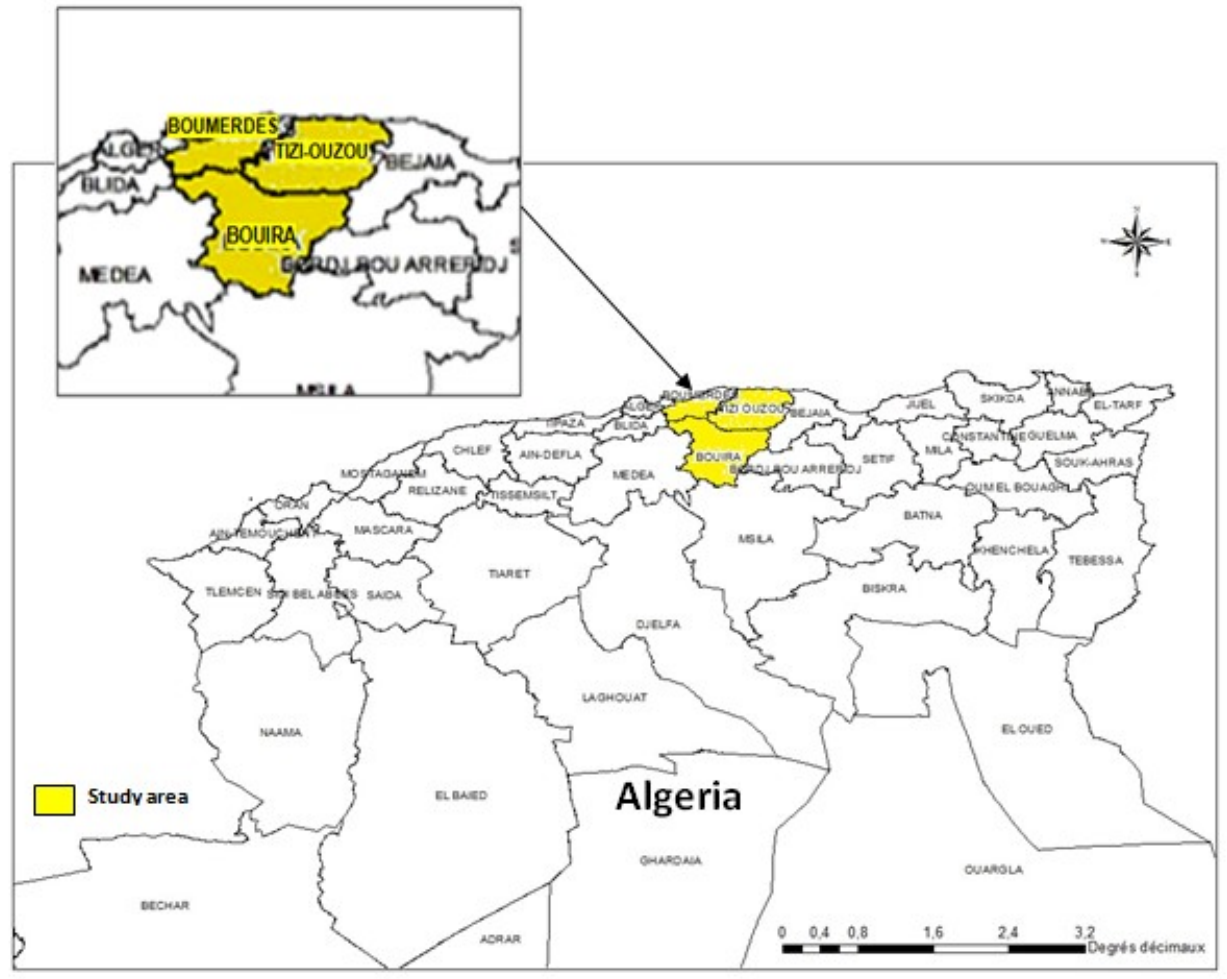

Figure 1: Geographical location of the study areas: Boumerdes, Tizi-Ouzou and Bouira
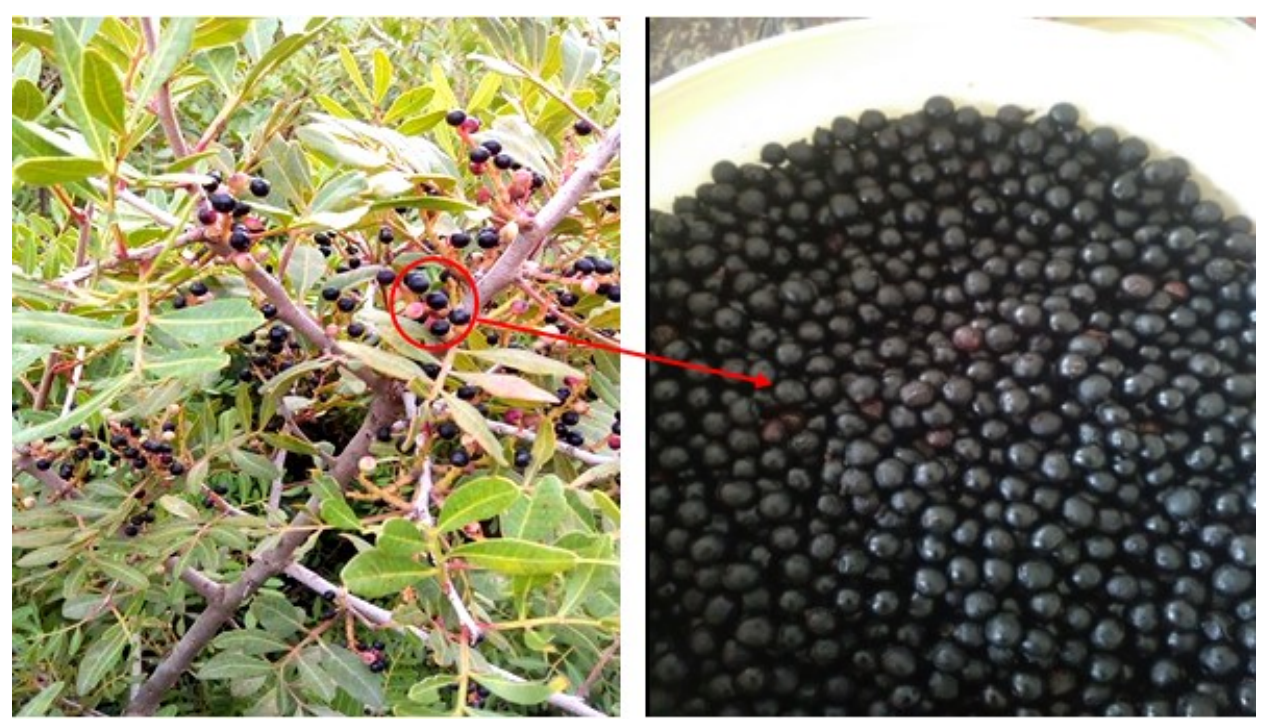

Figure 2: Mature fruits of Pistacia lentiscus L.

Methodology: The ethnobotanical study was conducted for five months, from November 2016 to March 2017, with regular field visits and face-to-face interviews in the form of a questionnaire that was given to herbalists, pharmacists and individuals in contact with the medicinal plants of the three study areas (Boumerdes, Tizi-Ouzou and Bouira). 120 interviews were conducted with 40 people per region. During each interview, we collected all the information about the survey and the plant (Pistacia lentiscus L). Thus, the profile of each survey includes his age, his level of education. The data collected for each plant include the common local name, uses, the part used, the method of preparation and the therapeutic indications. The 
ethnobotanical information collected from each area (Boumerdes, Tizi-Ouzou and Bouira) were processed, analysed, and compared by calculating:

- Frequencies of plant knowledge by age group.

- The percentage of plant knowledge by level of study.

- The percentage of lentisk use in the three study areas.

- The consensus value for plant part (CPP) using :

$\mathrm{CPP}=\mathrm{Px} / \mathrm{Pt} \quad$ (Monteiro et al., 2006)

Where Px: number of quote from the part of the

plant

Pt: total number of citations from all parts of the plant

- Frequencies of diseases treated with lentisk in the three study areas

- The uses of the plant (alone or in combination)

Phytochemical study: Phytochemical screening is a qualitative test that makes it possible to determine the various chemical compounds present in the plant, by colouring and precipitation reactions. These tests were carried out either on the powder or on the infused at $20 \%$ of lentisk fruits from the three provenance. The characterization methods used derive from those described by Harbone (1998). The screening was performed for various biochemical like total tannins, Gallic tannins, condensed tannins, anthocyanins, saponins, alkaloids, flavonoids, mucilage, glycosides and starch.

\section{RESULTS AND DISCUSSION}

Knowledge of the plant by age group: The data processing allowed us to obtain the graph of Fig. 3, which shows that in the three study areas (Boumerdes, Tizi-ouzou and Bouira), people over 60 have a frequency of knowledge of $P$. lentiscus that varies between $48 \%$ and $62 \%$. Then come the age groups [40-60], [20-40], and finally the under 20 age group with respective frequencies between ( $32 \%$ and $45 \%),(2 \%$ to $5 \%)$ and $(0$ to $3 \%)$. These results show that knowledge of the properties and uses of the plant studied depends on the long experience and confidence of the populations of these regions in traditional medicine. This also indicates that the transmission of this knowledge to the new generation is at risk because it is not ensured (Anyinam, 1995). Information collected in other studies conducted by Hafsé et al. (2015) shows that the highest percentage $(41 \%)$ of users is represented by people aged 18 to 36 years, indicating that young people tend to use $P$. lentiscus significantly.
Morphological characterization: A comparative morphological study of lentisk seeds from three areas was carried out by biometric measurements: a batch of 100 seeds was used for each provenance to measure the length of each seed with a vernier calliper. The length in $\mathrm{mm}$ of each fruit is taken from the point of attachment of the fruit to the branch at the end of the fruit. For the average weight of the seed, three lots of 100 seeds from each region were separately measured using an analytical balance with a precision of $0.01 \mathrm{~g}$. The evaluation of the weight of 1000 seeds focused on the seeds of the three regions. This parameter is one of the components of agronomic performance. This measure is mainly considered as an essentially varietal criterion which depends very much on the cultivation conditions which influence it very significantly. The mass of the 1000 lentisk seeds of the three study areas was determined according to the following formula:

PGM $(\mathrm{g} / \mathrm{dm})=\mathrm{P} \times[(100-\mathrm{H})] / 100$

$P$ : mass in grams of 1000 whole grains

$\mathrm{H}$ : grain water content

g/dm: grams per dry matter

The statistical evaluation has been done through analysis of variance (One-way ANOVA) to determine differences between means at $(p<0.05)$, using Statistica 7.1 (StatSoft Inc, France).

Knowledge of lentisk by level of study: In the two study areas (Boumerdes and Bouira), 50\% of the surveyed users of lentisk have a secondary level, while the other half correspond to the different intellectual levels (20\% primary, $20 \%$ illiterate and $10 \%$ university) and (20\% illiterate, $20 \%$ university and $10 \%$ primary) for the regions of Boumerdes and Bouira respectively (Fig.4: $a$ and b).For the region of Tizi-Ouzou $40 \%$ of people who have knowledge of the plant are academics, followed by those with secondary level and illiterate with $30 \%$ and $20 \%$ respectively, while those with little knowledge of the lentisk have a primary level $(10 \%)$ (Fig. 4: c).These results indicate that the categories that have information on lentisk in the Bouira and Boumerdes regions have a secondary level, while those from the Tizi-Ouzou region have the university level. Therefore, we can conclude that this information was transmitted through technology and books. 


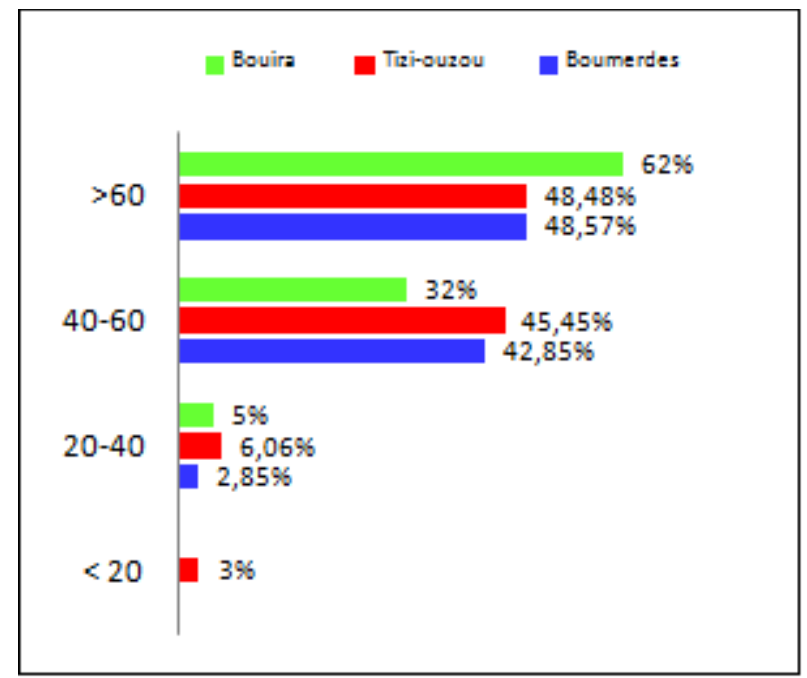

Figure 3: Frequencies of plant knowledge by age group in three study areas
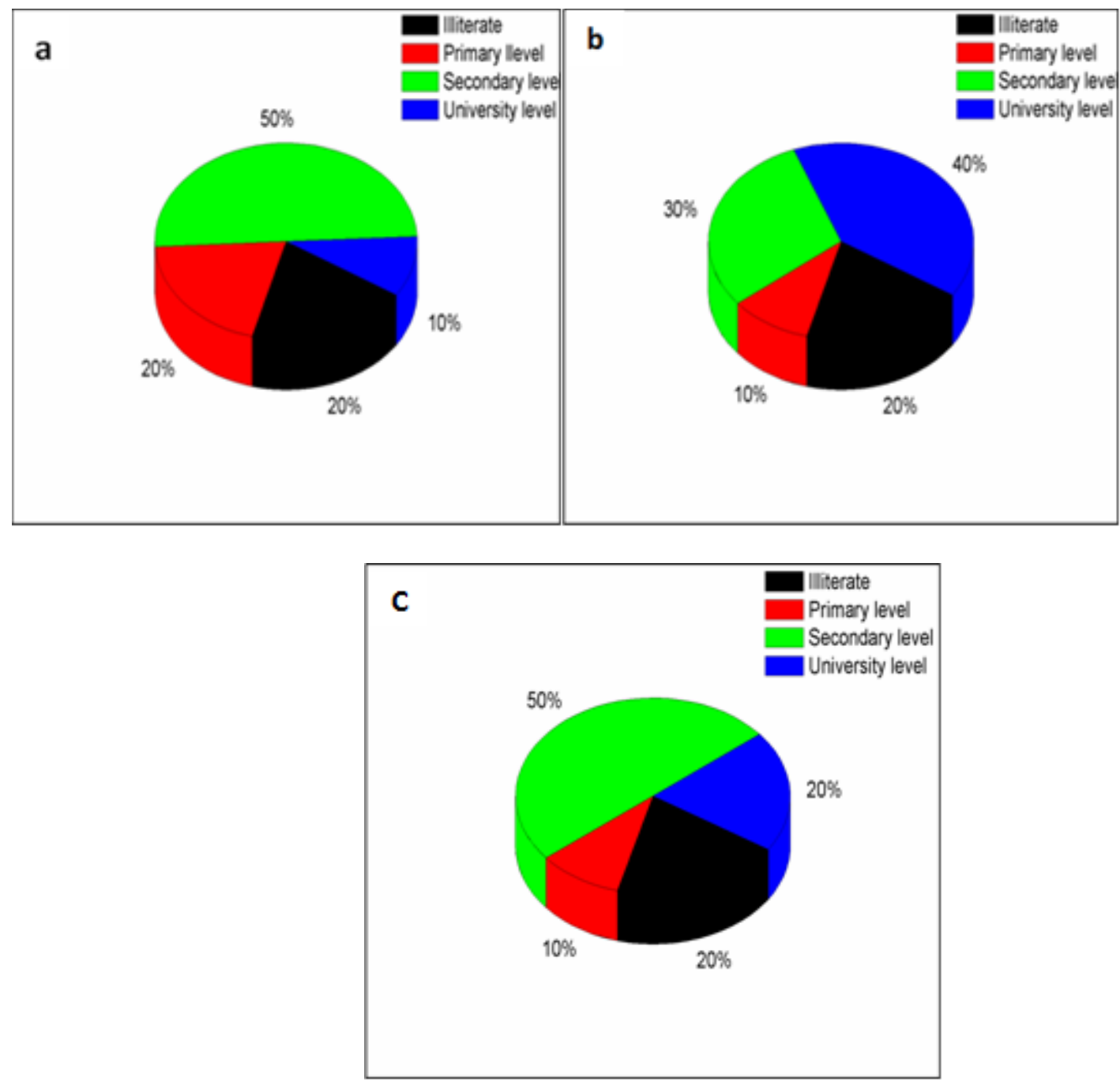

Figure 4: The percentage of plant knowledge by level of study (a: in Boumerdes, b: in Tizi-ouzou, c: in Bouira) 
Frequency of use of the lentisk according to their origin: The highest percentage of users of the Mastic Pistachio plant was recorded in the areas of Bouira and Boumerdes with a rate of $73 \%$ and $76 \%$ respectively, followed by that of Tizi-Ouzou with $52.5 \%$ (Fig.5). This strong use of lentisk can be explained by the availability, the free and the proximity of the plant compared to the high price of imported medicinal plants. Most people in the three regions use the plant

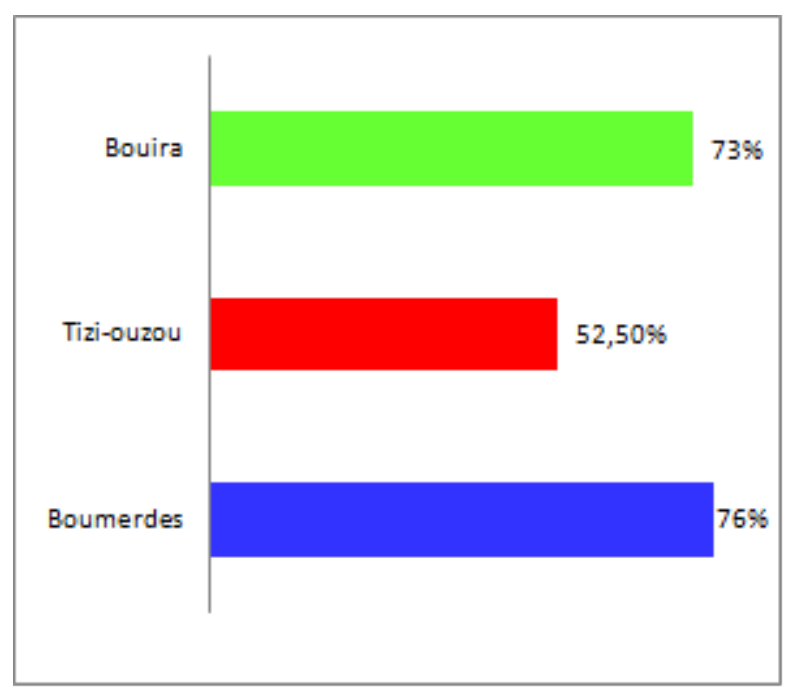

Figure 5: The percentage of lentisk use in the three study areas

Used part of the plant: The respondents in the three regions use lentisk in traditional medicine; in particular, leaves, fruits, stems and oils, alone or in combination with a different percentage (Fig. 7).Regarding the region of Bouira, the set of leaves, fruits and oils are the most used with a percentage of $37.5 \%$, the most used part in the region of Tizi-Ouzou and Boumerdes is the leaves with $17,5 \%$ and $20 \%$ respectively. These results confirm those found by Bammou et al. (2015), whose leaves are the part of the plant most used in Morocco, in the region of Meknes, with a percentage of $100 \%$ and $77 \%$ in northern Morocco (Taounate) (Hafsé et al., 2015). However, in other studies, they found that the fruit is the most used because it is rich in oil (Abdeldjelil et al., 2016).Calculation of the consensus value for a part of the plant (Consensus value for plant part (CPP), shows that the fruit, represented by the fatty oil, is the most used product of the lentisk in the region of Bouira with (0.38) followed by leaves (0.33) and fruits $(0.28)$. However, in the other regions, the leaves are the most used with (0.44 and 0.39); followed by fixed oils (0.36 and 0.31$)$ and finally fruits $(0.17$ and 0.29$)$. These alone, with a percentage that varies between $85 \%$ and $94 \%$ among the three study regions. It has been found that the plant is used alone according to the informants of the study areas, because its effectiveness does not need another element. The other informants $(5.5 \%$ of Boumerdes, $15 \%$ of Tizi-Ouzou and $5.27 \%$ of Bouira) use lentisk in combination with honey, ginger and propolis (Fig.6).

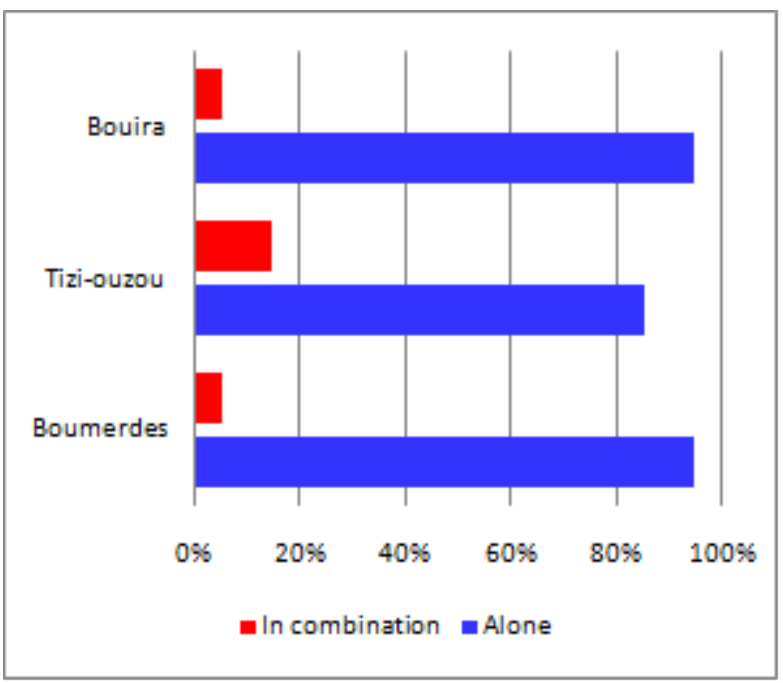

Figure 6: The uses of the plant (alone or in combination) in the three study areas

values represent respectively the Boumerdes and IïziOuzou zones. Only one informant mentioned the stem (0.02) of the plant in the region of Boumerdes, for his interest on the digestive apparatus.

Therapeutic uses of Pistacia lentiscus L.: The ethnobotanical survey revealed that all products of $P$. lentiscus were consumed mainly for the treatment of certain types of diseases, such as respiratory problems, with $55.26 \%$ of users in the Bouira region, $29.72 \%$ of Boumerdes and $22.22 \%$ for Tizi-ouzou. The lentisk also used for the treatment of disorders of the digestive system, with rates varies between 24, 32 and 50\% recorded in the three study areas (Fig.8). These results are comparable with those found by other studies (Bammou et al., 2015; Hafsé et al., 2015). Pistacia lentiscus L. was also indicated for the treatment of disorders of the circulatory system, allergies and skin problems, with varying percentages depending on the region. This confirms the results found by in vivo studies (on rabbits) concerning the external use of fixed oils, especially as healing (Djerrou et al., 2011; Maameri et al., 2014; Abdeldjelil et al., 2016). 


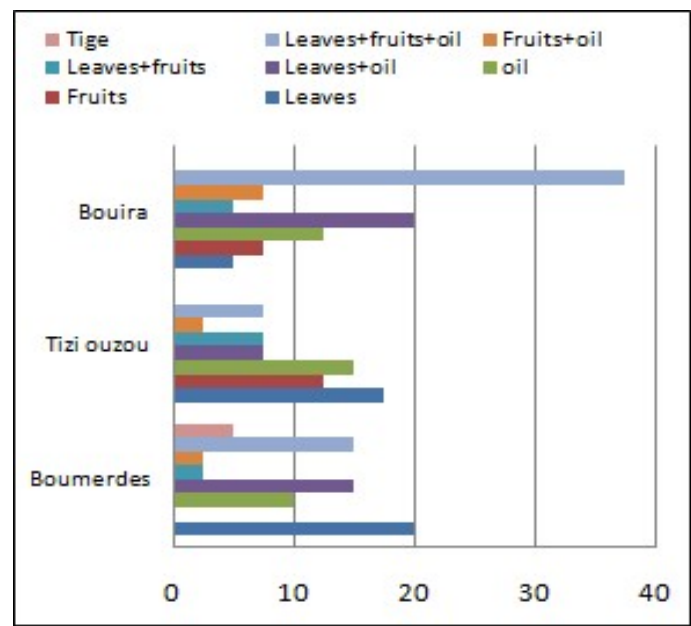

Figure 7: Frequencies of the part of the plant used in the three studv areas

Phytochemical study: The results of phytochemical analysis were given in the Table 2. Phytochemical

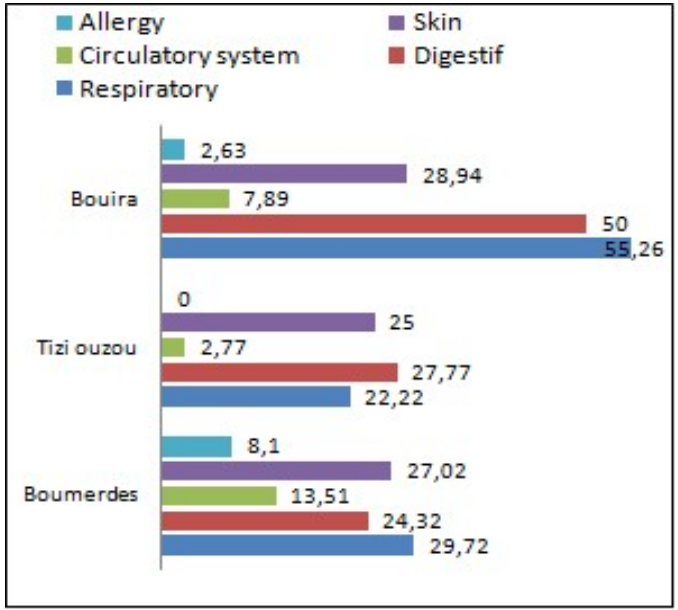

Figure 8: Frequencies of diseases treated with lentisk in the three study areas

screening was performed on the infused at $20 \%$ of $P$. lentiscus fruits from different study areas.

Table 2: Phytochemical analysis of extracts from fruits of Pistacia lentiscus $L$.

\begin{tabular}{l|l|l|l|l}
\hline Chemicals & Positive reactions & Boumerdes & Tizi-Ouzou & Bouira \\
\hline Total tannins & Blue black colour & ++++ & ++++ & ++++ \\
\hline Gallic Tannins & Dark blue colour & ++++ & ++++ & +++ \\
\hline Condensed tannins & Red colour & +++ & ++++ & +++ \\
\hline Anthocyanins & Red colour & +++ & ++++ & ++ \\
\hline Saponins & formation of froth & - & - & - \\
\hline Alkaloids & Red precipitate & - & - & - \\
\hline Flavonoids & Orange red colour & +++ & ++++ & ++ \\
\hline Mucilage & Formation of a flaky precipitate & ++ & + & +++ \\
\hline Glucosides & Brick red colour & ++ & ++ & ++ \\
\hline Starch & Purple blue colour & ++++ & ++++ & ++++ \\
\hline
\end{tabular}

$(-)$ : absence

$(+)$ : presence in small quantities

$(++)$ : presence in average quantity

$(+++)$ : presence in significant amount

$(++++)$ : presence in very large quantities

Preliminary results showed that $P$. lentiscus from the three study areas contains the majority of secondary metabolites, in the form of condensed tannins, Gallic tannins, anthocyanins and flavonoids and other substances such as mucilage, glucosides and starch, with varying intensity depending on the region. Anthocyanins and alkaloids are absent in $P$. lentiscus fruit from all the study areas. According to Tsai et al. (2008), the phytochemical profile of a plant is directly related to environmental conditions such as climate, geographical location, temperature, photoperiod, vegetative stage, etc. which affect the synthetic pathways of active plant compounds. These results confirm the findings of Belhachat et al. (2017). Compounds such as flavonoids have antioxidant and anti-inflammatory activities and play a positive role in the treatment of cardiovascular and neurogenerative diseases (Wang \& Mazza, 2002).The tannins exist either in catechic or Gallic form. They are held as good remedies in the treatment of respiratory diseases and 
cough (Bouchet et al., 2000), also exercising a certain antidiarrheal activity and used in the treatment of dermatitis (Aron \&Kennedy,2008). The presence of tannins in the various organs of the plant explains its prescription as a regulator of gastrointestinal functions.

\section{Morphological characterization}

The length of the seeds: The analysis of variance for the seed length variable of the different zones (Boumerdes, Bouira and Tizi-ouzou) (Fig.9), did not reveal difference between the provenances. The average seed length varies between $4.6 \pm 0.065 \mathrm{~mm}$ and $5.1 \pm 0.61 \mathrm{~mm}$. Other studies on the genus Pistacia were carried out on the analysis of the morphological variability of eight spontaneous populations of Pistacia atlantica in Algeria; have shown that fruit size varies between 4 and $9 \mathrm{~mm}$ (Belhadj et al., 2008).

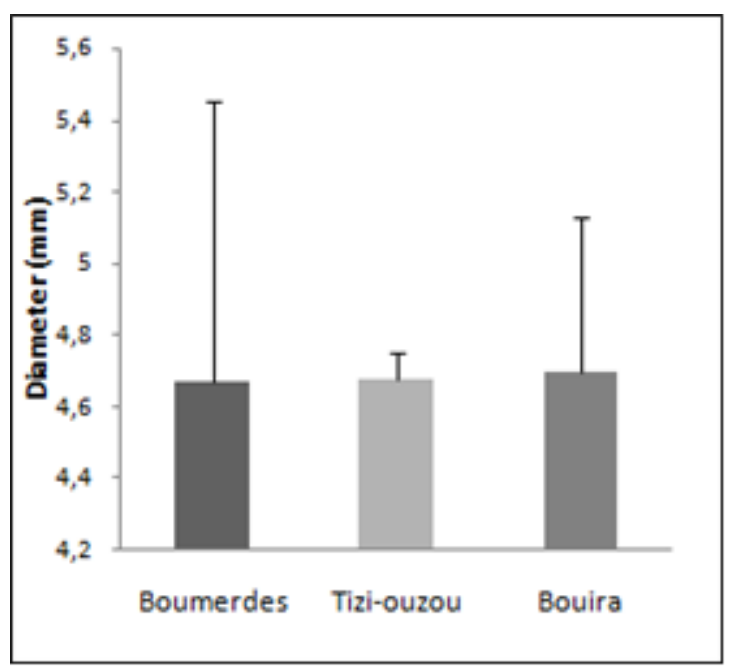

Figure 9: Average diameter of lentisk seeds from studv areas
The weight of the seeds: Analysis of variance for the mean seed weight variable (Fig.10) revealed a significant difference between the seeds harvested in Bouira and those of Boumerdes and Tizi-Ouzou ( $P$ $<0.05$ ). The average weight of all seeds is $0.079 \pm$ $0.029 \mathrm{~g}$. The Bouira region appears to be the source with the lightest seeds $(0.046 \pm 0.013 \mathrm{~g})$ while the heaviest seeds are observed in the Boumerdes and Tizi-Ouzou origins with $0.0953 \pm 0.013 \mathrm{~g}$ and $0.098 \pm$ $0.054 \mathrm{~g}$, respectively.

1000-seed weight: Significant difference of the weight of 1000 seeds was obtained between the fruits of the three areas (Fig.11). The fruits of the Boumerdes region recorded the highest weight $(52.01 \mathrm{~g} / \mathrm{dm})$ while the regions of Bouira and Tizi-Ouzu recorded the lowest weight with $41.01 \mathrm{~g} / \mathrm{dm}$ and $28.05 \mathrm{~g} / \mathrm{dm}$, respectively.

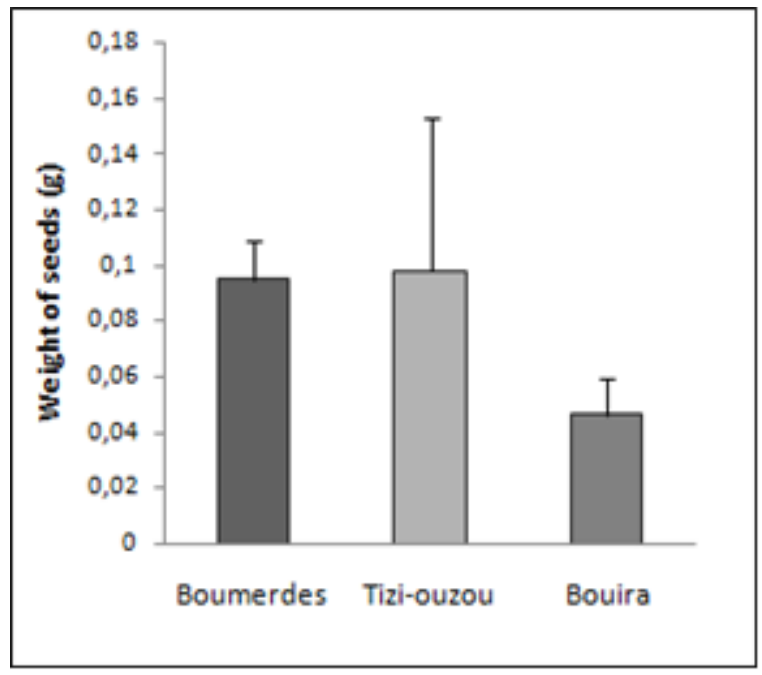

Figure 10: Average weight of the seeds of the study areas

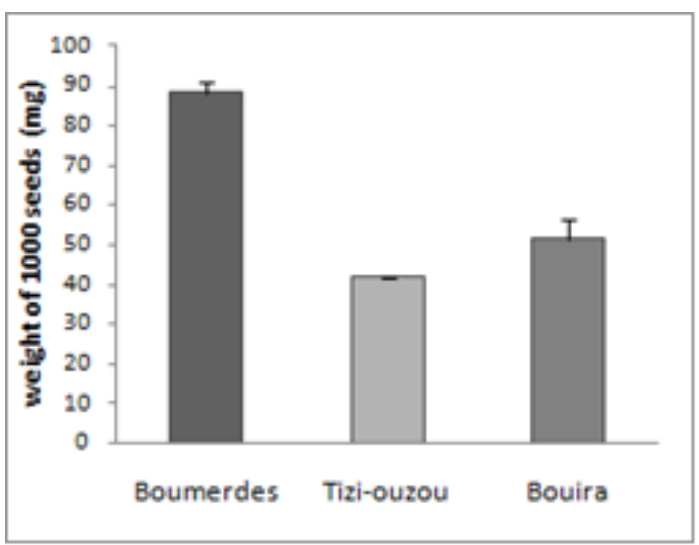

Figure 11: Weight of 1000 seeds of lentisk from study areas 
In this study, it was observed that the low-lying region is the one that represents the average weight and weight of 1000 seeds the most important. The type and variety of berries plants may account for differences in the

\section{CONCLUSION}

The ethnobotanical survey made it possible to specify the different uses of $P$. lentiscus by the populations of Boumerdes, Bouira and Tizi-Ouzou (Northern Algeria) as well as to collect information on the nature of the users. This revealed a multitude of results that show that the majority of users of this plant are aged and belong to an age group of 40 to 60 years, and have varying intellectual levels between high school and university. This does not reassure the good transmission of the culture of use of $P$. lentiscus as a medicinal plant. In addition, it has been found that most of the uses of $P$. lentiscus in the study areas are therapeutic, that fruit oil is the most used part of the plant followed by leaves and fruits at a very low rate. In the same way, on the whole of the treated diseases, the

\section{ACKNOWLEDGEMENTS}

The authors wish to thank the interviewees, especially the herbalists and pharmacists from the three cities of northern Algeria (Boumerdes, Tizi-ouzou and Bouira),

\section{REFERENCES}

Abdeldjelil MC, 2016. Effets cicatrisants de produits à base d'huile de lentisque (Pistacia lentiscus L.) sur les brulures expérimentales chez le rat. Thèse de Doctorat en sciences veterinaries, 80-101.

Anyinam C, 1995. Ecology and ethnomedicine: exploring links between current environmental crisis and indigenous medical practices. Soc. Sci. Med., 4: 321-329.

Aron PM and Kennedy JA, 2008. Flavan-3-ols: nature, occurrence and biological activity, Mol. Nutr. Food Res., 52, 79-104.

Azzi R, Djaziri R, Lahfa F, Sekkal FZ,Benmehdi H, Belkacem N,2012. Ethnopharmacological survey of medicinal plants used in the traditional treatment of diabetes mellitus in the North Western and South Western Algeria. J. Med. Plants, 6:2041-50.

Bammou M, Daoudi A, Slimani I, Najem M, Bouiamrine EH, Ibijbijen J, Nassiri L, 2015. Valorisation du lentisque «Pistacia lentiscus L. »: Étude ethnobotanique, screening phytochimique et results obtained as well as possible geographic origin of plants, genotypes considered, environmental conditions (soil, climate) (Belhachat et al., 2017).

digestive affections, the respiratory problems and the allergies represent the most cited diseases. Phytochemical screening of this plant showed that fruits from different regions were rich in anthocyanins, condensed tannins, Gallic tannins and flavonoids of varying intensity, while devoid of saponoside and alkaloids. The results obtained constitute a valuable source of information, which should be the subject of additional pharmacological studies to validate their popular use and to isolate bioactive compounds from fruits. Furthermore, this study contribute to the valorization of this forest product, by using the $P$. lentiscus whole fruit and benefit from its bioactive components that can be used as an ingredient in functional foods.

who helped to collect valuable information about the plant.

pouvoir antibactérien. J. Appl. Biosci., 86: 7966- 7975 .

Belhachat D, Aid F, Belhachat L, Belhachat M, 2017. Phytochemical screening and in vitro antioxidant activity of Pistacia lentiscus berries ethanolic extract growing in Algeria. Med. J. Nutrition Metab., 10: 273-285.

Bouchet N, Lévesque J, Pousset JL, 2000. HPLC isolation, identification and quantification of tannins from Guiera senegalensis. Phytochem. Anal., 11: 52-56.

Charef M, Yousfi M, Saidi M, Stoccker P, 2008. Determination of the fatty acid composition of Acorn (Quercus), Pistacia lentiscus seeds growing in Algeria. J. Am. Oil Chem. Soc. 85: 921-924.

Dhifi W, Jelali N, Chaabani E, Beji M , Fatnassi S, Omri S, Mnif W, 2013. Chemical composition of Lentisk (Pistacia lentiscus L.) seed oil. Afr. J. Agric. Res., 8(16): 1395-1400.

Djerrou Z, Hamdi-Pacha Y, Belkhiri A M, Djaalab H, Riachi F, Serakta M, Boukeloua A, Maameri 
Z, 2011. Evaluation of Pistacia lentiscus fatty oil effects on glycemic index, liver functions and kidney functions of New Zealand rabbits. Afr. J. Trad. Complement Altern. Med. 8, (5 Suppl): 214-219.

Gupta VK, Tuohy MG, Lohani M, O'Donova A, 2015. Biotechnology of bioactive compounds: sources of applications, ISBN 978-1-11873349-3

Hafsé M, Fikri Benbrahim K, Farah A, 2015. Enquête ethnobotanique sur l'utilisation de Pistacia lentiscus au Nord du Maroc (Taounate). Int. J. Innov. Appl. Stud., 13 (4): 864-872.

Harbone JB, 1998. Phytochemical methods: A guide to modern technique of plant analysis. Chapman \& Hall Thomson Science (UK), 3éme edition: 203-236.

Maameri-Habibatni Z, 2014. Pistacia lentiscus L.: Evaluation pharmacotoxicologique. Thèse de Doctorat en Sciences. Université Constantine 1, Algérie. $102 \mathrm{p}$.

Monteiro JM, De Albuquerque UP, Lins-Neto EM, De Araújo EL, De Amorim EL, 2006. Use patterns and knowledge of medicinal species among two rural communities in Brazil's semi-arid northeastern region. J. Ethnopharmacol.105, (1-2), 173-86.

Tiwari P, KumarB, Kaur M, Kaur G, Kaur H, 2011. Phytochemical screening and Extraction: A Review. Internationale Pharmaceutica Sciencia, 98-106.

Tsai PJ, Wu SC, Cheng YK, 2008. Role of polyphenols in antioxidant capacity of Napier grass from different growing seasons. Food Chem., 106, 27-32.

Wang J, Mazza G, 2002. Effects of anthocyanins and other Phenolic compounds on the Production of Tumour Necrosis Factor a in LPS/IF N-y Activated RAW 264.7 Macrophages. J. Agric.Food Chem., 50, 4183. 